\title{
Appendix: Text of the Preamble of the Nagoya Protocol
}

\author{
(numbering suggested by authors)
}

The Parties to this Protocol,

1. Being Parties to the Convention on Biological Diversity, hereinafter referred to as "the Convention",

2. Recalling that the fair and equitable sharing of benefits arising from the utilization of genetic resources is one of three core objectives of the Convention, and recognizing that this Protocol pursues the implementation of this objective within the Convention,

3. Reaffirming the sovereign rights of States over their natural resources and according to the provisions of the Convention,

4. Recalling further Article 15 of the Convention,

5. Recognizing the important contribution to sustainable development made by technology transfer and cooperation to build research and innovation capacities for adding value to genetic resources in developing countries, in accordance with Articles 16 and 19 of the Convention,

6. Recognizing that public awareness of the economic value of ecosystems and biodiversity and the fair and equitable sharing of this economic value with the custodians of biodiversity are key incentives for the conservation of biological diversity and the sustainable use of its components,

7. Acknowledging the potential role of access and benefit-sharing to contribute to the conservation and sustainable use of biological diversity, poverty eradication and environmental sustainability and thereby contributing to achieving the Millennium Development Goals,

8. Acknowledging the linkage between access to genetic resources and the fair and equitable sharing of benefits arising from the utilization of such resources,

9. Recognizing the importance of providing legal certainty with respect to access to genetic resources and the fair and equitable sharing of benefits arising from their utilization,

10. Further recognizing the importance of promoting equity and fairness in negotiation of mutually agreed terms between providers and users of genetic resources,

11. Recognizing also the vital role that women play in access and benefit-sharing and affirming the need for the full participation of women at all levels of policymaking and implementation for biodiversity conservation, 
12. Determined to further support the effective implementation of the access and benefit-sharing provisions of the Convention,

13. Recognizing that an innovative solution is required to address the fair and equitable sharing of benefits derived from the utilization of genetic resources and traditional knowledge associated with genetic resources that occur in transboundary situations or for which it is not possible to grant or obtain prior informed consent,

14. Recognizing the importance of genetic resources to food security, public health, biodiversity conservation, and the mitigation of and adaptation to climate change,

15. Recognizing the special nature of agricultural biodiversity, its distinctive features and problems needing distinctive solutions,

16. Recognizing the interdependence of all countries with regard to genetic resources for food and agriculture as well as their special nature and importance for achieving food security worldwide and for sustainable development of agriculture in the context of poverty alleviation and climate change and acknowledging the fundamental role of the International Treaty on Plant Genetic Resources for Food and Agriculture and the FAO Commission on Genetic Resources for Food and Agriculture in this regard,

17. Mindful of the International Health Regulations (2005) of the World Health Organization and the importance of ensuring access to human pathogens for public health preparedness and response purposes,

18. Acknowledging ongoing work in other international forums relating to access and benefit-sharing,

19. Recalling the Multilateral System of Access and Benefit-sharing established under the International Treaty on Plant Genetic Resources for Food and Agriculture developed in harmony with the Convention,

20. Recognizing that international instruments related to access and benefit-sharing should be mutually supportive with a view to achieving the objectives of the Convention,

21. Recalling the relevance of Article $8(\mathrm{j})$ of the Convention as it relates to traditional knowledge associated with genetic resources and the fair and equitable sharing of benefits arising from the utilization of such knowledge,

22. Noting the interrelationship between genetic resources and traditional knowledge, their inseparable nature for indigenous and local communities, the importance of the traditional knowledge for the conservation of biological diversity and the sustainable use of its components, and for the sustainable livelihoods of these communities, 
23. Recognizing the diversity of circumstances in which traditional knowledge associated with genetic resources is held or owned by indigenous and local communities,

24. Mindful that it is the right of indigenous and local communities to identify the rightful holders of their traditional knowledge associated with genetic resources, within their communities,

25. Further recognizing the unique circumstances where traditional knowledge associated with genetic resources is held in countries, which may be oral, documented or in other forms, reflecting a rich cultural heritage relevant for conservation and sustainable use of biological diversity,

26. Noting the United Nations Declaration on the Rights of Indigenous Peoples, and

27. Affirming that nothing in this Protocol shall be construed as diminishing or extinguishing the existing rights of indigenous and local communities,

Have agreed as follows: 